\title{
HIPERTROFIA DA INFORMAÇÃO SOB A ÓTICA DOS CONCEITOS DE VERDADE E PÓS- VERDADE
}

\author{
HYPERTROPHIC INFORMATION UNDER THE VIEW OF TRUTH AND POST-TRUTH \\ CONCEPTS
}

${ }^{1}$ Doutoranda em Ciência da Informação (PPGCI/UFPB), Professora do Departamento de Ciência da Informação da UFBA.

E-mail: denisebs23@gmail.com

2 Doutor em Ciência da Informação pela UNESPMarília, Professor do PPGCI/UFPB

E-mail: henry.poncio@gmail.com

${ }^{3}$ Doutora em Educação pela UFPB, Professora do PPGOA/UFPB

E-mail: daluzprof@gmail.com

\section{ACESSO ABERTO}

Copyright: Esta obra está licenciada com uma Licença Creative Commons Atribuição 4.0 Internacional. (cc) $\mathrm{EY}$

Conflito de interesses: Os autores declaram que não há conflito de interesses.

Financiamento: Não há.

Declaração de Disponibilidade dos dados: Todos os dados relevantes estão disponíveis neste artigo.

Recebido em: 20/09/2019.

Revisado em: 01/10/2019.

Aceito em: 10/10/2019.

\section{Como citar este artigo:}

SAMPAIO, Denise Braga; OLIVEIRA, Henry

Poncio Cruz de; OLEGÁRIO, Maria da Luz.

Hipertrofia da informação sob a ótica dos conceitos de verdade e pós-verdade.

Informação em Pauta, Fortaleza, v. 4, n.
Denise Braga Sampaio ${ }^{1}$

Henry Poncio Cruz de Oliveira ${ }^{2}$

Maria da Luz Olegário 3 especial, p. 9-30, nov. 2019. DOI:

https://doi.org/10.32810/2525-

3468.ip.v4iEspecial.2019.42597.9-30.

\section{RESUMO}

Desvela as relações existentes entre verdade, pós-verdade e informação na perspectiva de conceituar a hipertrofia da informação na Ciência da Informação. Utiliza como aporte metodológico a pesquisa exploratória, bibliográfica e a análise conceitual de Walker e Avant, como forma de responder às questões: o que é hipertrofia da informação? Quais são suas características e implicações em uma sociedade dita informacional? Ampara-se nos seguintes objetivos: criar um conceito, para a Ciência da Informação, de hipertrofia da informação, e analisar seu relacionamento com a verdade e a pós-verdade. A análise mostra que a hipertrofia da informação está intimamente ligada com a pós-verdade e a constituição de fake news, ao que se notaram em páginas verificadoras de fatos (fact-cheking) classificações que se tangenciam com o conceito, comprovando sua congruência com o tema.

Palavras-chave: Pós-verdade. Informação. Fake News. Hipertrofia da informação.

\section{ABSTRACT}

It reflects about the relationships between truth, post-truth and information into the perspective of conceptualizing information hypertrophy in Information Science. It uses as methodology the exploratory, bibliographical research and the conceptual analysis of Walker and Avant, to answer the questions: what is information hypertrophy? What are its characteristics and 
implications in a so-called informational society? It is supported by the following objectives: to create a concept, for Information Science, of hypertrophic information, and to analyze its relationship with truth and post-truth. The analysis shows that information hypertrophy is closely linked with post-truth and fake news constitution, as noted in fact-checking pages some classifications that tangent with the concept, proving its congruence with the theme.

Keywords: Post-truth. Information. Fake News. Hypertrophic information.

\section{INTRODUÇÃO}

A informação perpassa por todo o processo humano que compreende a história, sobretudo a história registrada. Sua importância é patente desde a quebra do código nazista, a partir de Alan Turing, até a cura de doenças, pelas descobertas científicas. Passa também por pequenos eventos, como narrativa de fatos locais, que constituem memórias individuais e coletivas. A informação é, portanto, não somente "seiva da ciência" (LE COADIC, 2004), mas de um arranjo biossocial muito maior, pois compreende a vida humana.

Destacamos, já desnudando a temática aqui proposta, que a informação é a matéria prima da verdade, que pode ser lapidada ao bel prazer do emissor. Por isso, discussões sobre pós-verdade, fake news e mentira são cada vez mais pertinentes, dado que a informação pulula, na atual sociedade, da multiplicidade de crenças, fatos e atos. Ela nasce e se molda, ou, como sugere sua gênese, toma forma. Estar imergido na Sociedade da Informação é entender a dinâmica existente entre essa matéria prima e os processos desencadeados a partir da nossa interação com ela.

De posse dessas reflexões e do cenário que se descortina sob a perspectiva da pós-verdade (DUNKER, et al., 2017), percebemos que a interação entre verdade, opinião e público pertence a uma lógica contemporânea de consumo desenfreado de informações das mais diversas fontes, cujo filtro principal é a simplicidade de 'exposição' dos fatos, que não lhe assegura a qualidade. As redes sociais tornam-se, invariavelmente, uma das principais fontes de consulta e exposição de notícias (CASADEI, 2013) e de pareceres de pessoas não doutas no assunto, ou seja, informações são consumidas e opiniões emitidas nestes ambientes, como um ciclo retroalimentado. Vale destacar que a pós-verdade, como ver-se-á de forma mais explícita em sua referida seção, não se trata de mera mentira, mas se constitui de artifícios diversos para comover pessoas e mobilizar a opinião pública em prol de determinada ação ou ideologia. A pós-verdade 
está constituída tanto dessas mentiras 'puras', como de um conjunto de verdades pensadamente ordenadas para estabelecer uma narrativa desejável. Um desses artifícios é a própria informação, que, de seiva da verdade, pode tornar-se seiva também da pósverdade, em suas mais variadas formas de exposição, comportando-se como uma infotoxina (PHILLIPS, 1996). Essa infotoxina pode gerar a hipertrofia da informação, objeto de estudo deste trabalho.

Segundo o dicionário de etimologia chileno (RODRIGUEZ, 20--), 'hipertrofia' é uma palavra cuja origem se deu no seio da medicina francesa, em 1819, resultado dos componentes léxicos gregos uாع $\rho$ (hypér), que significa "acima do normal", "em excesso"

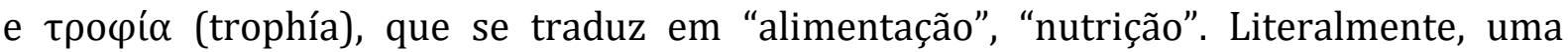
sobrealimentação ou nutrição em excesso (RODRÍGUEZ, 20--). Na comunicação, a hipertrofia da informação é citada por alguns autores, como Marques (et al., 2009); Muniz Sodré (BARRETO, 2012); Künsch (2006); Almeida (2010); Ferrari (2005), no entanto, na área de Ciência da Informação o tema é, ainda, pouco discutido. 0 que seria essa hipertrofia da informação? Quais são suas características e implicações em uma sociedade dita informacional? Diante destas questões, objetivamos, portanto, criar um conceito, para a Ciência da Informação, sobre esta hipertrofia, extensivamente, analisar seu relacionamento com a verdade e a pós-verdade.

\section{PROCEDIMENTOS METODOLÓGICOS}

A pesquisa, sob o ponto de vista de seus objetivos, se caracteriza como exploratória, dado que o produto gerado é a conceituação do termo 'hipertrofia da informação', cuja variação é 'informação hipertrófica'. Segundo Prodanov e Freitas (2013, p. 51), a pesquisa exploratória trata de investigação em "[...] fase preliminar, [e tem] como finalidade proporcionar mais informações sobre o assunto [...] possibilitando sua definição e delineamento [...]. Assume, em geral, as formas de pesquisa bibliográfica e estudo de caso". Segundo Gil (2008, p. 27).

As pesquisas exploratórias têm como principal finalidade desenvolver, esclarecer e modificar conceito e ideias [...] são desenvolvidas com o objetivo de proporcionar visão geral, de tipo aproximativo, acerca de determinado fato. Este tipo de pesquisa é realizado especialmente quando o tema escolhido é pouco explorado [...] 
A conceituação do termo, dentro da Ciência da Informação (CI), faz-se necessária, primeiramente, por se tratar de uma anomalia do objeto de estudo da área, mas também por compor um processo hodierno de manipulação das informações (e notícias), em uma sociedade pautada na pós-verdade advinda de interações ciberativistas e passionais. Para melhor apreender este contexto, o estudo se valeu, complementarmente, de levantamento bibliográfico a respeito das interações entre verdade, pós-verdade e informação em livros, sobretudo da área de filosofia, e artigos da área de comunicação e CI (especialmente no Portal de Periódicos da Capes), com uso dos termos 'verdade', 'pós-verdade', 'fake news', 'fact-cheking' e "hipertrofia da informação" (com aspas duplas). Esta última palavra não obteve nenhum resultado na plataforma, no entanto, ao se buscar pelo termo no Google, obtiveram-se 26 resultados, todos, apenas citando o termo, mas não o conceituando.

Como o objetivo central é a criação de um conceito, na Ciência da Informação, para a hipertrofia da informação, utiliza-se neste estudo a análise conceitual, entendendo que

Um conceito é uma ideia ou construção mental elaborada acerca de um fenômeno. São termos referentes aos fenômenos que ocorrem na natureza ou no pensamento. São representações cognitivas, abstratas, de uma realidade perceptível formada por experiências diretas ou indiretas. Os conceitos podem ser empíricos ou concretos (observados pelos sentidos) ou abstratos (não observáveis). Sua função primária é permitir que indivíduos possam descrever situações e se comunicar efetivamente (FERNANDES et al., 2011, p. 1151).

A análise conceitual, na perspectiva de Walker e Avant (apud FERNANDES, 2011), obedece a oito passos que ajudam a entender melhor dado conceito. São eles:

Quadro 1 - Passos da Análise Conceitual e aplicação

\begin{tabular}{|c|c|c|}
\hline Passos & Conceitos dos passos & $\begin{array}{c}\text { Passos da pesquisa segundo } \\
\text { método }\end{array}$ \\
\hline (1) seleção do conceito & $\begin{array}{l}\text { deve refletir o tópico ou a área de maior } \\
\text { interesse, sendo recomendável a escolha } \\
\text { de um conceito que esteja ligado à área } \\
\text { de experiência profissional (prática, } \\
\text { pesquisa, ensino, administração) e que } \\
\text { tenha despertado atenção e preocupação } \\
\text { na pessoa. }\end{array}$ & Hipertrofia da informação \\
\hline $\begin{array}{l}\text { (2) determinação dos } \\
\text { objetivos da análise } \\
\text { conceitual }\end{array}$ & $\begin{array}{l}\text { finalidade da análise conceitual que se } \\
\text { pretende realizar }\end{array}$ & $\begin{array}{l}\text { Conceituar hipertrofia } \\
\text { Informação na CI }\end{array}$ \\
\hline $\begin{array}{l}\text { (3) identificação } \\
\text { possíveis usos } \\
\text { conceito }\end{array}$ & $\begin{array}{l}\text { busca na literatura para se ter uma ideia } \\
\text { de como o conceito em questão está } \\
\text { sendo enfocado ou aplicado }\end{array}$ & $\begin{array}{l}\text { Buscas exploratórias nos campos } \\
\text { de Comunicação e Ciência da } \\
\text { Informação }\end{array}$ \\
\hline $\begin{array}{l}\text { (4) determinação dos } \\
\text { atributos críticos ou }\end{array}$ & $\begin{array}{l}\text { se identificam palavras ou expressões } \\
\text { que aparecem repetidamente na }\end{array}$ & $\begin{array}{llll}\text { Será } & \text { apresentado } & \text { na } \\
\text { apresentação } & \text { e } & \text { discussão } & \text { dos }\end{array}$ \\
\hline
\end{tabular}




\begin{tabular}{|c|c|c|}
\hline Passos & Conceitos dos passos & $\begin{array}{l}\text { Passos da pesquisa segundo } \\
\text { método }\end{array}$ \\
\hline essenciais & $\begin{array}{l}\text { literatura, que mostram a essência do } \\
\text { conceito. } \\
\text { Esses atributos constituem } \\
\text { características que expressam o } \\
\text { conceito, as quais atuam como elementos } \\
\text { para diagnósticos diferenciais, isto é, } \\
\text { para discriminar o que é uma expressão } \\
\text { do conceito daquilo que não é. Nos casos } \\
\text { em que o conceito é muito abstrato, os } \\
\text { seus atributos, geralmente, têm também } \\
\text { alto grau de abstração. }\end{array}$ & resultados \\
\hline $\begin{array}{l}\text { (5) construção de um } \\
\text { caso modelo }\end{array}$ & $\begin{array}{l}\text { elaboração de um exemplo, baseado na } \\
\text { vida real, do uso do conceito, que inclua } \\
\text { seus } \\
\text { atributos essenciais. }\end{array}$ & $\begin{array}{l}\text { Será visto na apresentação e } \\
\text { discussão dos resultados }\end{array}$ \\
\hline $\begin{array}{l}\text { (6) desenvolvimento } \\
\text { de outros casos }\end{array}$ & $\begin{array}{l}\text { limítrofes, relacionados, contrários } \\
\text { inventados e ilegítimos. Servem para } \\
\text { auxiliar na decisão quanto aos atributos } \\
\text { essenciais do conceito. Entre esses casos, } \\
\text { chamamos atenção para dois deles que, } \\
\text { no nosso entendimento, melhor } \\
\text { cumprem a meta ora exposta: o caso } \\
\text { contrário e o caso limítrofe. O caso } \\
\text { contrário provê exemplo do "não } \\
\text { conceito". Já o caso limítrofe, constitui } \\
\text { aquele evento ou instância que contém } \\
\text { alguns dos atributos essenciais do } \\
\text { conceito sob análise, mas não todos eles. }\end{array}$ & $\begin{array}{l}\text { Será visto na apresentação e } \\
\text { discussão dos resultados }\end{array}$ \\
\hline $\begin{array}{lr}\text { (7) Identificação } & \text { de } \\
\text { antecedentes } & \text { e } \\
\text { consequências } & \text { do } \\
\text { conceito } & \end{array}$ & $\begin{array}{l}\text { levantamento de incidentes ou eventos } \\
\text { que acontecem a priori ao fenômeno } \\
\text { (necessários para a sua ocorrência) e a } \\
\text { posteriori (eventos ou situações que } \\
\text { surgem ou resultam da presença do } \\
\text { fenômeno). }\end{array}$ & $\begin{array}{l}\text { Desenvolvido no referencial } \\
\text { teórico do trabalho }\end{array}$ \\
\hline $\begin{array}{l}\text { (8) Definição de } \\
\text { referências empíricas } \\
\text { para os atributos } \\
\text { essenciais }\end{array}$ & $\begin{array}{l}\text { referentes empíricos são categorias ou } \\
\text { classes de fenômenos observáveis que, } \\
\text { quando presentes, demonstram a } \\
\text { ocorrência do conceito, possibilitando, } \\
\text { assim, sua definição operacional. Em } \\
\text { muitos casos, os atributos são idênticos } \\
\text { às referências empíricas. Quando os } \\
\text { conceitos são abstratos (autoestima, } \\
\text { tristeza), seus indicadores empíricos não } \\
\text { são diretamente observáveis, dependem } \\
\text { de medidas indiretas. }\end{array}$ & - \\
\hline
\end{tabular}

Fonte: baseado em FERNANDES (2011).

Para melhor entender o conceito de hipertrofia da informação em uma sociedade pós-verdadeira, é necessário que se revisite a filosofia clássica e a moderna, em suas discussões sobre verdade, mentira e o contemporâneo entendimento de pós-verdade, advindo do campo político e de comunicação. 


\section{PERCEPÇõES FILOSÓFICAS E POLÍTICAS SOBRE O CONCEITO DE VERDADE, MENTIRA E PÓS VERDADE}

Falar sobre verdade é fazer um exercício filosófico. Tal termo passou, ao longo do tempo, por diferentes conceituações, teorias e divisões. Um esboço da concepção de verdade pode ser visto em Platão, no mito da caverna (COSTA, 2010), em que a verdade se descortina na liberdade, com o romper dos grilhões e afastamento do mundo visto pelas sombras, para o mundo visto na perspectiva da luz. Essa iluminação é contemplada no mundo das ideias, mundo este onde os vícios e os subterfúgios não poderiam ofuscar os sentidos, com a expressão plena dos objetos como se apresentam. Para Platão, é na ideia que se desvela a verdade. Ela é a própria luz. Estar iluminado, portanto, não é a mais fácil das tarefas. Por esse motivo, aquele que conseguiu desbravar o que havia além da caverna, na tentativa vã de mostrar o que vira a seus companheiros, acaba desacreditado e ameaçada é a sua vida. Isso ocorre porque a verdade que se revela pelos olhos de outrem torna-se uma ruptura inaceitável àquilo que antes era a expressão mais plena do mundo, um mundo visto pelos olhos treinados para enxergar somente sombras.

A visão platônica abriu horizontes para entender a verdade de forma metafísica, transcendendo a experiência sensível, por meio da racionalização. Há dois mundos separados no pensamento de Platão: o mundo das aparências, ligado a todos os enganos provenientes da ordem da sensibilidade, e o mundo das Ideias, ligado à ordem da verdade. Em suma, a ordem da sensibilidade diz respeito às experiências singulares dos mais diversos indivíduos que se voltam para a realidade sempre em conformidade com suas paixões ou interesses, como ocorre atualmente, com o que chamaremos de pósverdade (SALZTRAGER; LOURENÇO, 2017). Essa forma de pensar a verdade foi base para o conceito de Heidegger, que associa a verdade com a liberdade.

\footnotetext{
A tarefa desse homem liberto [o que sai da caverna] não é fácil, pois ele se encontra no risco de perder-se no interior da caverna pelo simples motivo de ser atraído, puxado pela verdade que aí vige e serve de medida para todos. Outro risco corre ainda ele, que é aquele relacionado à revolta dos que acreditam que o que serve de medida no interior da caverna é o que aparece para eles como o mais desvelado, de modo que o homem liberto 'está ameaçado pela possibilidade de ser morto' (COSTA, 2010, p. 217).
}

Ou seja, essa liberdade é ameaçada não somente pelo outro, mas pela própria fragilidade do ser humano frente àquilo que lhe é natural, que lhe é comum, habitual. Há, 
então, uma relação constante entre velar e desvelar, entre trevas e luz, entre o já conhecido e o novo que se desnuda nessa luz. 0 ser humano, quando confrontado com o novo, tende a recusá-lo em um primeiro momento, para só então aceitá-lo. A esse respeito, na perspectiva do universo ideal de Platão, é pertinente a assertiva de Bauman (2012, p. 8), de que "é da natureza das ideias que elas nasçam como heresias perturbadoras e morram como ortodoxias aborrecidas". A ideia de que fala Bauman não é perfeita, idealizada e eterna, como em Platão, mas descontínua. Ela é própria de uma sociedade que imerge na liquidez. No entanto, a resistência ao novo é tanto presente para os que estavam presos na caverna mitológica de Platão - porque o novo, ou a verdade revelada, neste caso, pode ser assustador, quebrando modelos, rompendo com costumes até então consagrados - como em nossa contemporaneidade.

Para filósofos como Foucault e Benjamim, a verdade é contextual. Foucault entende a verdade como relacionada aos jogos de poder, sobretudo às narrativas das histórias oficiais, enquanto Benjamim entende que a verdade é composta por camadas (SALZTRAGER; LOURENÇO, 2017). No campo das ciências, a verdade está relacionada àquilo que comprovadamente não pode ser refutado. Tal entendimento vem do princípio da falseabilidade de Popper (1980). Este princípio versa que uma teoria é incorporada à ciência na medida em que não é refutada a partir de experimentos verificadores de sua invalidade. Exemplo disso, a lei da gravidade assevera que orbita sobre a terra uma força, chamada de gravidade, que puxa os corpos para seu centro e, ignorando-se a força do ar, todo corpo tende a cair, sempre que arremessado ou solto. Este experimento pode ser verificado em qualquer parte do globo terrestre, conferindo sempre o mesmo resultado: o encontro do objeto com o chão.

Segundo Descartes (1987), todo o ser humano possui bom senso, que é ter "a capacidade de bem julgar e distinguir o verdadeiro do falso" (DESCARTES, 1987, p.30). Ele assevera que o uso da razão faz com que o aluno alcance o conhecimento da verdade, sem seguir as autoridades escolásticas, por meio da dúvida e do questionamento (WATANABE; SOARES, 2011). Descartes, a partir de então, passou a distinguir o verdadeiro do falso considerando como verdadeiro tudo quanto pudesse ser conhecido de modo claro e distinto, e julgando falso tudo quanto não o pudesse (DESCARTES, 1987). Como é possível determinar esta clareza e esta distinção? 0 autor apresenta (DESCARTES apud VILELA; IZIDORO, 2013) algumas ações que podem levar o sujeito à verdade: (a) dúvida metódica; (b) análise; (c) síntese; (d) revisão. 
Segundo a Teoria da Correspondência, proposta por Tarski (2007), uma proposição é verdadeira se ela corresponde à realidade, se o que ela afirma de fato é uma proposição, um juízo ou uma sentença. É verdadeiro se, e somente se, reflete a realidade. Já para os adeptos da filosofia da ação, como Nietzsche (ARENDT, 2014), a verdade tem caráter utilitário, não contemplativo. Deste modo, a verdade, “[...] qualquer que seja o campo a que pertença, só é verdadeira pela sua efetiva utilidade, ou seja, por ser útil para estender o conhecimento ou para, por meio deste, estender o domínio do homem sobre a natureza, ou então por ser útil à solidariedade e à ordem do mundo humano" (ABBAGNANO, 2007, p. 998).

Essas perspectivas desveladas pelos filósofos são um importante caminho para se pensar não mais em verdade, mas verdades que se descortinam sob diferentes metodologias, a depender do instituto que as defenda. Por isso, Arendt (2014) denomina a verdade metafísica de Platão de verdade filosófica, enquanto a verdade científica, para

alcançar tal status, necessita de experimentações, método científico, comprovação e aceitação por pares para ter validade. No campo da política, esta advém de fatos, e Arendt (2014) a chama de verdade fatual. A autora entende que, na Modernidade, tal verdade inexiste, por sua constante ameaça, que a fluidez dos processos e os jogos de poder inserem sobre ela.

\subsection{Verdade, mentira e opinião na Modernidade}

O movimento de transição da Tradição para a Modernidade se deu por rupturas paradigmáticas de inversões de valores e pela crise da autoridade (ARENDT, 2014). Nietzsche (2007), um dos autores referência para este período e, como afirma Belo (1994), extemporâneo, entende a verdade, entre outras coisas, como objetivo do conhecimento e uma forma de ilusão, um valor, produzida pelo intelecto. 0 intelecto humano difere mulheres e homens dos demais animais, conferindo-lhes a capacidade de adaptação às situações, por meio da cognição. “O intelecto é um meio de conservação do indivíduo, para o manter, para conservar os mais fracos; desenvolve as suas forças capitais [...]" (BELO,1994, p. 214). Assim, na concepção nietzschiana, é da natureza humana a dissimulação. Esta serve para conferir aos mais fracos as armas necessárias à sobrevivência. Vale destacar que a visão de Nietzsche não carrega ideais maniqueístas que filósofos como Platão e Heidegger defendem, sob uma divisão engessada entre bem 
e mal, certo e errado. Para Nietzsche, o que move um sujeito a falar a verdade não é ela em si, mas as suas consequências, quando comparadas à mentira. Por existir uma moral que defende a verdade como sendo melhor aceita que a mentira, opta-se por ela em favor de suas benesses, não pelo ideal do 'fazer o bem' por meio da honestidade e da verdade.

A perspectiva nietzschiana (BELO, 1994) obedece a três paradigmas, (1) a do animal que luta pela vida; (2) a do conhecimento e, por fim; (3) a da linguagem. Segundo Belo (1994), em sua releitura do filósofo alemão, o primeiro paradigma diz respeito ao uso da dissimulação e da ilusão para garantir a sobrevivência, sendo estas duas ações precursoras da verdade. Neste sentido, emular, disfarçar-se, criar arapucas para capturar uma caça, fingir-se de morto, ou fingir-se adequado a determinada situação em que ser minoria é ameaça são alguns dos subterfúgios utilizados para garantir essa manutenção da vida. O paradigma do conhecimento pode ser melhor entendido nas palavras de Camargo (2008, p. 98):

\begin{abstract}
A vontade de verdade é a busca metafísica por um fundamento último para o conhecimento, é acreditar que através da razão e das construções intelectuais se atinge uma espécie de verdade primordial. A vontade de engano é a maneira como Nietzsche enxerga esta vontade de verdade. 0 filósofo entende a razão e as demais construções intelectuais como construções históricas - e, neste sentido, suas proposições são chamadas de falsas - mas entende que há uma necessidade de se acreditar em tais falsificações como se fossem verdades. Esta é a ilusão necessária que Nietzsche chama de vontade de engano. A vontade de verdade, a busca da verdade e a crença nesta verdade decorrem da necessidade de se acreditar nas construções históricas e culturais, ou seja, decorre da vontade de engano.
\end{abstract}

Por fim, o paradigma da linguagem diz respeito à arbitrariedade da palavra. A linguagem (NIETZSCHE, 2007) possui dois estágios, um individual e anárquico e outro social, determinado sob estruturas de poder. A palavra, nessa perspectiva, é constituída de forma normalizante, metafórica em relação ao objeto, hierarquizada e uniforme. "É a semântica social que traz consigo a lei e a verdade" (BELO, 1994, p. 219). Por esse motivo, Nietzsche, valendo-se de Kant, acredita que, por meio da palavra, não se pode chegar à verdade, dado que esta é, substancialmente, a coisa em si. Ora, se a palavra é temporal, culturalmente construída e espacialmente limitada, a verdade não pode ser expressa por ela, não como universalizantei.

Tais questões evidenciam o caráter dinâmico das sociedades e instituições que a compõem. Como falar, então, sobre uma ideia de verdade? Para Nietzsche (2007), a sociedade, em suas formas de poder, obriga os sujeitos a mentir, "[...] o homem mente 
inconscientemente, segundo costumes centenários, costumes de longo tempo [...] [o sentimento de verdade é o sentimento] de ser obrigado a designar [...] ao que busca a lei" (BELO, 1994, p. 234) "conforme uma convenção consolidada, mentir em rebanho num estilo a todos obrigatório" (NIETZSCHE, 2007, p. 37).

Diante disso, o autor se pergunta então qual o impulso para a verdade e o que seria ela. Ele mesmo responde ao afirmar que a verdade é:

Um batalhão móvel de metáforas, metonímias, antropomorfismos, enfim, uma soma de relações humanas, que foram enfatizadas poética e retoricamente, transpostas, enfeitadas, e que, após longo uso, parecem a um povo sólidas, canônicas, e obrigatórias: as verdades são ilusões, das quais se esqueceu que o são, metáforas que se tornaram gastas e sem força sensível, moedas que perderam sua efígie e agora só entram em consideração como metal, não mais como moedas (NIETZSCHE, 2007, p. 36-37).

A verdade, então, seria uma ilusão massificante, ligada a uma vontade de potência, a um impulso. A vontade de potência é a necessidade da vida de exercer ações para emancipar-se, uma dessas ações pode ser a dominação do outro. Ser verdadeiro, honesto, é, então, uma forma de colocar-se em posição superior em relação àquele que mente, dado que o honesto não precisa mentir para sobreviver, e a moral (socialmente construída e aceita) o coloca nessa posição de superioridade.

[...] em trabalhos posteriores, o autor [...] investiga a ligação da verdade com o medo, ou seja, com a necessidade de manter uma realidade, um 'mundo verdadeiro', por trás da aparência. A vontade de verdade seria, então, a busca incessante pela calma e segurança de uma estrutura fixa de 'realidade' para se opor ao mundo impossível de se perceber corretamente - seria uma maneira de viver quando já não se tem vontade de potência, a coragem para encarar o mundo de frente, com todas as suas dúvidas e desafios (SIQUEIRA, 2014, não paginado).

Vale destacar, ainda sobre Nietzsche (2007), que o autor categoriza a verdade sob três tipos: as verdades agradáveis, (conservadoras da vida e desejadas pelo homem); as verdades puras ou sem consequências (que pode ser entendidas como conhecimento) e as verdades prejudiciais, ou destruidoras. Neste ponto, fica evidente o caráter funcional que se atribui à verdade. As verdades destruidoras, aquelas que causam rupturas dolorosas às estruturas de poder, são, invariavelmente, invisibilizadas ou aniquiladas, enquanto as demais são estimuladas a aparecer para manter a ordem estabelecida, dado que a verdade só pode valer enquanto atendente às convenções que a sustentam e à lei.

Arendt (2014) faz duras críticas à visão utilitarista de Nietzsche. A autora defende que a verdade existe, mas passa por uma crise atrelada à crise da autoridade. A 
ascensão da política burguesa na sociedade, a crise na educação e a massificação da opinião pública abalam as estruturas de verdade, fazendo valer a forma em desfavor do conteúdo. Para Arendt (2014), a relativizações da verdade, transformação da verdade fatual em opinião e da opinião em fato, bem como a desqualificação de autoridades, são as principais fontes de destruição da verdade na Modernidade em que viveu a autora e hodiernamente.

A verdade fatual (ARENDT, 2014), residente no campo da política, não como sua coparticipe, mas como uma inquilina indesejada e escondida que, quando aparece, é desmoralizada, se inoportuna. Isso ocorre com grande força na modernidade, em que a mentira se institucionaliza na política e toma proporções e status de organizada (ARENDT, 2014). A mentira organizada reside na ação, assim como tudo que diz respeito à política, e tem por objetivo mudar uma realidade ao bel prazer do seu portador. 0 perigo da mentira está, entre outras coisas, na construção de narrativas históricas enviesadas.

\subsection{Pós-verdade}

0 termo 'pós-verdade' (em inglês, post-truth) ganhou destaque em 2016, sendo apontado como a palavra do ano pelo Dicionário Oxford, graças às eleições americanas do referido período, ocasião em que se elegeu presidente o empresário Donald Trump. 0 termo é apontado, pelo Oxford, como "a circunstância em que fatos objetivos têm menos influência na formação de opinião pública do que os apelos emocionais e as opiniões pessoais" (BOLER; DAVIS, 2018, p. 75). A pós-verdade é a efetivação e ampliação do que destacara Hanna Arendt (2014) sobre a crise da verdade. Os fatos são preteridos pelo sentimento desperto ou pelo desejo de despertar sentimentos nos interlocutores.

Acerca disso, Christian Dunker et al. (2017, p. 17) elencam em 'Ética e pósverdade':

O relativismo cultural da verdade foi subitamente invertido pelo real da guerra ao terror. A tolerância religiosa inverte-se na perseguição aos mulçumanos [...] em 2011, a verdade das armas químicas que justificavam o ataque ao Iraque mostrou-se uma ficção. 0 fato de que presidentes e agências de Estado pratiquem mentiras técnicas como essa, retóricas [...], jurídicas (como a corrupção dentro da lei), apenas replica a maquiagem de balanços (que estava por trás das bolhas imobiliárias de 2008) e o cinismo como discurso básico do espaço público e da vida laboral. 
A autoridade do Estado e seu status de portador da verdade são postos em xeque pela descoberta da população a respeito destes e de outros pontos de influência das narrativas oficiais, como forma de comoção da opinião pública para que esta apoie determinadas ações importantes política e economicamente para os EUA, mas que, de forma 'crua', não seriam aceitas pelo povo. Era necessário gerar empatia pela causa e antipatia pelo que se punha como empecilho. Apesar de o termo ter sido posto em destaque recentemente, tal prática é antiga, sobretudo ao rememorarmos a historiografia, permeada por maniqueísmos e construção dos heróis e dos vilões (LE GOFF, 1990) como forma de inspiração do orgulho nacional.

Atualmente, a pós-verdade ganhou força com a popularização das redes sociais. A troca de informações, constituição de diálogos em tempo real, de forma incorpórea, e a possibilidade de replicação exponencial são um forte motor da pós-verdade. Nesse sentido, as eleições americanas de 2016 geram, até hoje, debates acalorados, uma vez que investigações apontam o uso de robôs artificialmente inteligentes, desenvolvidos na Rússia, que replicavam desinformação nas redes sociais como forma de gerar emoção e comoção na opinião pública americana (BOLER; DAVIS, 2018). A proliferação de desinformação gerou um ambiente de insegurança e descrédito das mídias (BOLER; DAVIS 2018). 0 que fora verdade em dado momento, ou vendido como tal, em outro momento passa a não mais valer. Como afirma Dunker (2017, p. 19), “a pós-verdade é antes de tudo uma verdade contextual, que não pode ser escrita, posta no bolso e reapresentada amanhã, como garantia de fidelidade, compromisso ou esperança gerada pela palavra".

No contexto da pós-verdade, o discurso atua como elemento principal das narrativas em detrimento do que se enuncia. 0 'como' deve ser atraente, independente de o 'quê' se diz, "surge assim uma espécie de avaliação permanente da retórica empregada, que induz e valoriza declarações impactantes e menosprezo por autoridades ou especialistas que possam desmenti-la" (DUNKER, 2017, p. 24). Nesse sentido, a estética é mais importante do que o conteúdo. Este contexto tornou-se propício à proliferação das fake news. Ora, se há uma crise nas instituições 'detentoras' da verdade, então todos tanto podem buscar como produzir suas próprias verdades. 0 discurso pósverdadeiro, para ecoar tais 'verdades', se vale de três traços, destacados por Dunker (2017): a recusa do outro, uma retórica icônica e, por fim, a vida em formato de demanda. Resumidamente, discursos de invisibilização ou recusa do outro são 
produzidos e reproduzidos com apelo imagético e linguístico (vídeos, sons, memes, textos curtos) em pacotes de informação rapidamente consumíveis e, geralmente, ambíguos.

A necessidade da velocidade de consumo das informações faz padecer outra necessidade, a da qualidade da informação. Nesse sentido, as anomalias informacionais, como em um processo de metástase, dominam as infovias e multiplicam-se como desinformação qualificada por sua forma atraente. Nesse cenário, as fake news são absorvidas pelos leitores de forma acrítica e replicadas rapidamente.

A pós verdade transfere a autoridade da ciência e do jornalismo sério para a produção e as opiniões criando certos efeitos [...] nada mais tentador que pular os dados técnicos, os detalhes e as incertezas de um problema real com uma boa opinião de conjunto, ainda mais se ela for sancionada pela 'razão universal', que limpa o terreno e dispensa de considerar certos ângulos adicionais e excessivos [...]" (DUNKER, 2017, p. 39).

Balém (2017) entende a fake news como uma mentira em forma de notícia. 0 foco das fake news são os cidadãos comuns e sua principal função é mexer com a emoção destas pessoas, tanto gerando hate speech (discurso de ódio), como uma imagem positiva do ator central da notícia, que pode ser um personagem, um grupo político, uma instituição ou ideologia. As fake news, segundo Wardle (2017), são divididas em sete categorias: (1) sátira ou paródia, (2) falsa conexão, (3) conteúdo enganoso, (4) falso contexto, (5) conteúdo impostor, (6) conteúdo manipulado, (7) conteúdo fabricado. Para a Agência Lupaii, especialista em checagem de fatos (fact-cheking) e signatária da International Fact-cheking Networkiii (IFCN), as notícias são classificas em: verdadeira; verdadeira, mas, ainda é cedo para dizer; exagerada; contraditória; insustentável; falsa; de olho. Enquanto a Aos Fatosiv, também signatária da IFCN, classifica em: exagerada, imprecisa, verdadeira e falsa. Essas divisões são importantes, pois mostram possíveis relações da informação com o grau de verdade ou inverdade das notícias. Essas relações são ligadas pelo grau de anomalia da informação, que tanto pode ser hipertrófica, como pura desinformação.

\section{ACEPÇÕES DA INFORMAÇÃO E DE SUA HIPERTROFIA NA CIÊNCIA DA INFORMAÇÃO: ASPECTOS CONCEITUAIS E POLÍTICOS}

Para melhor entender a verdade, é necessário que retornemos à afirmação que fizemos na introdução, de que a informação é sua matéria-prima. Esta assertiva é, no primeiro momento, perigosa, mas necessária à discussão. Revisando a etimologia da 
palavra informação, temos que esta deriva do verbo em latim informare/informatio, cujo significado é dar forma ou colocar em forma (MESSIAS, 2005). A informação, a partir de sua etimologia, pode ser entendida como uma exteriorização, sob determinada forma, inteligível a outrem. É, nesse sentido, tornar tangível e acessível algo outrora velado não a quem possui a informação, mas a quem se pretende expor. Voltando ao mito da caverna, é a enunciação do sujeito que narra aos seus colegas de morada o que vira, mas não somente ela em si, é também o processo.

\begin{abstract}
Se considerar-se que o homem se utiliza da informação e da comunicação para travar relações entre si e o meio em que vive, pode-se inferir que a informação pode dubiamente representar o momento em que o homem delimita o pensamento/ideia (substância imaterial) e molda-o, transmuda-o para uma forma simbólica, capaz de ser apreendida e comunicada. Paralelamente, indica o "conteúdo" propriamente dito da mensagem, nesse sentido, tem-se que a informação é o resultado do ato de informar (conteúdo) e o próprio ato (forma) (MESSIAS, 2005, p. 21).
\end{abstract}

0 ato de informar é carregado de símbolos, da perspectiva do emissor e do repertório cultural e ideológico que o permeia. Mas não é mera representação, ela é, “[...] mais precisamente, a articulação de uma compreensão pragmática de um mundo comum compartilhado" (CAPURRO, 1992 apud GÓMEZ, 2002, p. 32). Esse entendimento pressupõe que receptor e emissor devem compartilhar do mesmo repertório linguístico para que haja intercâmbio de informações e de suportes que possibilitem esse intercâmbio. Por exemplo, a inteligibilidade deste artigo para você que lê só é possível por compartilharmos do mesmo universo simbólico e linguístico e pela existência de próteses comunicacionais, como a escrita e o suporte, no caso, o próprio artigo, que tanto pode estar em meio eletrônico, como físico. Essa extensão da inteligência pela materialização é uma das perspectivas de entendimento da informação. No entanto, a informação não é isenta, pura e perfeita, como pensa o paradigma platônico da Ciência da Informação (CAPURRO, 1985 apud GÓMEZ, 2002), e não o é justamente pela falibilidade, pelos desejos e pela finitude de quem as apreende, o próprio ser humano, além de seu caráter político (CAPURRO; HJORLAND, 2007). “A informação não é um artefato estável e passivo, é interativa, coletiva e performativa. A informação é, portanto, política na medida em que serve como meio para decidir em quem se pode, ou não confiar [...]" (KLINGEL; BOYD, 2013, p. 989, tradução nossav).

Pensando nisso, Demo (2000) assevera que a informação não é sinônimo de conhecimento e que a oferta demasiada deste produto não implica em uma sociedade 
bem informada, muito pelo contrário. O pensamento de Demo é consoante com o entendimento de neofilia, evidenciado por Almeida (2010), que trata do desejo incontrolável pelo novo e por conhecer tudo. 0 autor entende que as informações, para aplacar esse desejo pelo novo, são consumidas como pílulas, e que a humanidade se torna dependente 'química' delas (ALMEIDA, 2010). Este processo de consumo anômalo de informações pode gerar um comportamento informacional também anômalo, e o que antes era entendido como constituinte da construção de conhecimentos passa a ser o da atrofia do intelecto.

Paradoxalmente, vivemos na sociedade do conhecimento, sociedade tecnológica ou sociedade da informação, mas, se informação é o princípio do conhecimento, a hipertrofia da informação se traduz na incapacidade de produção do conhecimento e, consequentemente, da experiência com o conhecimento. Então, uma sociedade hipertrofiada pela informação é uma sociedade atrofiada de experiência. A velocidade e a superficialidade com que a informação é veiculada nos diferentes meios de comunicação (internet, televisão, rádio, revistas) não permitem que a experiência aconteça (RANGEL, 2009, p. 222).

Complementa este raciocínio a enumeração das cinco características que evidenciam o caráter manipulativo da informação, apontadas por Demo (2000, p. 40).

Primeiro, a sociedade continua bastante 'desinformada', seja porque lhe chega tendencialmente informação residual, ou porque se lhe impõe informação oficial, ou porque se entope atabalhoadamente. Segundo, há informação de classe superior e inferior, cuja variação está em função como regra do poder aquisitivo de cada um. [...] Terceiro, abunda na praça informação imbecilizante, seja por conta da distorção por vezes clamorosa, mas igualmente pela exploração das futilidades da mídia [...] Quarto, a mídia está muito distante de sua função pública, porque corresponde a um estilo afrontoso de apropriação privada, dirigida por trâmites comerciais estritos. Não existe qualquer controle público digno de nota que preserve os interesses do público. Sem recair na "censura", sempre impertinente e no fundo equivocada, é preciso que a sociedade possa pressionar adequadamente a mídia, para que os interesses comerciais não sejam os únicos. Quinto, a potencialidade informativa dos novos meios de comunicação está ainda presa a acessos elitistas, e quando traduzida em teleducação, tende fortemente ao instrucionismo. Como bem mostra igualmente a biologia, o instrucionismo é intrinsecamente imbecilizante.

De posse dos conceitos acima, de informação, verdade, pós-verdade, pode-se agora tecer o conceito de informação hipertrófica, ou hipertrofia da informação, a partir do entendimento do termo "hipertrofia", que já fora introduzido, mas que pode ser melhor apreciado na seção que segue. 


\section{UM CONCEITO DE HIPERTROFIA DA INFORMAÇÃO PARA CIÊNCIA DA INFORMAÇÃO}

Na fisiologia, o termo hipertrofia significa uma adaptação das células e tecidos diante de uma maior exigência de trabalho, seja fisiológica (esperada, normal) ou patológica. No que tange aos nossos músculos, é quando a massa muscular total aumenta, daí chama-se hipertrofia muscular (HALL; GUYTON, 2017). Hipertrofia, desta forma, é o "crescimento de um órgão ou tecido [...] causado pelo aumento de tamanho das células, enquanto a hiperplasia [...] é o crescimento anormal de um tecido, mas produzido pelo aumento do número de células, não por seu tamanho" (RODRÍGUEZ, 20-, não paginado). A hiperplasia é também conhecida como hipertrofia numérica. De posse disso, ao se analisar o entendimento de hipertrofia da informação na Comunicação, temse, de forma recorrente, a ideia de grande quantidade de informações. Nas palavras de Guerra (2003, não paginado),

[...] hoje vivemos em um mundo de muitas conexões e poucos vínculos. Vivemos os excessos da modernidade, informação, imagens, individualismo, com hipertrofia da informação e atrofia do entendimento. Porque 'de tantas árvores, já não se consegue ver o bosque'.

Barreto (2012, não paginado) evidencia a crença de Muniz Sodré de que:

[...]a 'hipertrofia da informação' leva a um 'desaparecimento da cultura' e a uma 'informação como mera quantidade ou dado', resultando em uma 'cultura como produção mercantil'. De acordo com o homenageado, 'o principal objetivo da 'mídia' atual é se apropriar do tempo do outro', transformando-se em uma 'mídia conectiva, mas não informativa.

Já Künsch (2006) crê que a hipertrofia da informação está ligada à necessidade de tudo ver (onividência), de estar em toda parte (onipresença), sendo, as pessoas, assediadas por câmeras, imagens, informações. O ser humano, em suas palavras, tornase um devorador dessas imagens, um "devorador devorado [...] De tanto ver, às vezes, já não vemos" (KÜNSCH, 2006, p. 41).

Os autores acima convergem no entendimento de uma oferta e consumo exagerados de informação, ou, utilizando-se da alusão de Almeida (2010), - da informação como pílula - uma superdosagem. Como toda superdosagem, o consumo exagerado de informações causa o efeito oposto do que versa suas recomendações. 0 que era seiva do conhecimento e da verdade torna-se fonte de ignorância e falsas certezas. 0 processo de dúvida e crítica é posto de lado em nome da velocidade e da 
facilidade de apreensão, gerando o que Almeida (2010) chama de 'bulimia intelectual', como se fossemos acometidos pelo que o autor chama de Síndrome de Fausto (desejo de conhecer tudo). A forma de manter este vício é pela atualização constante de Tecnologias da Informação e da Comunicação (TIC) que propiciem uma gama maior de informações, em tempo hábil, fazendo os aplicativos e páginas de portais serem executados de forma ótima, mesmo que nosso processamento intelectual não acompanhe o processamento das máquinas. Nesse sentido, a hipertrofia da informação, a priori, pode ser entendida como a manifestação assediante e em grande escala de informações e meios para sua propagação em consonância com o desejo de seu consumo. Essa ideia de quantidade parece ser mais aproximativa do entendimento de hiperplasia (ou hipertrofia numérica) do que de hipertrofia, ao se levar em consideração as informações como células, dado que a hipertrofia é o aumento da célula, que faz aumentar o órgão, e não o aumento do conjunto de células.

A partir disso, há outra possibilidade conceitual para o termo, tomando por base o entendimento primário e biológico de hipertrofia, no sentido não de várias informações, mas de uma única que é construída de forma imoderada. A hipertrofia da informação, nesse sentido, seria a construção da narrativa de um fato de forma hiperbólica e sensacionalista, não se constituindo em mentira, ou fake news, mas no fato em si, cuja possibilidade futura soe nebulosa, implicando em ação necessária do interlocutor. Exemplos, os mais diversos, podem ser verificados na rede, como na greve da Polícia Militar (PM) do Estado do Ceará, deflagrada em 2012, perto do réveillon de Fortaleza, um dos maiores do país.

Relatos de violência, verdadeiros ou não, difundiram-se pelas redes sociais, sobretudo no Twitter. Vídeos de crimes de anos anteriores e fotos de ocorrências em outros estados foram difundidos como se fossem no Ceará. Houve também ocorrências reais. O POVO confirmou ter havido arrastões na Vila Velha, no Henrique Jorge e na Varjota. Comerciantes fecharam as lojas mais cedo. [...] Havia rumores de arrastões - não confirmados - em municípios vizinhos, como Acarape e Barreira. No dia 3 de janeiro, a crise chegou ao ápice. Boatos que começaram no dia anterior se massificaram em redes sociais e no boca-a-boca da população. 0 medo foi legitimado quando empresas e até órgãos públicos começaram a fechar as portas por temor de arrastões. Feriado informal foi instituído. Na Internet, imagens falsas mostrando ações de criminosos na Cidade se multiplicavam. Avenida ficaram desertas em pleno segundo dia útil do ano. Supermercados, hospitais colégios, restaurantes, academias, lotéricas, consultórios médicos, bancas de revista e padarias, cada minuto um novo estabelecimento supostamente era vítima dos criminosos. 0 que antes era uma queda de braço entre Governo e manifestantes passou a ter impactos econômicos e sociais. No fim da tarde, poucos estabelecimentos se mantiveram abertos. [...] A insatisfação com o impasse tomou conta da população e foi determinante para que o governador Cid Gomes cedesse e 
aceitasse as reivindicações impostas pelo comando de greve-(CAVALCANTE; FIRMO, [2018]).

Percebe-se, pelo relato acima, que, além da circulação massiva de fake news, outro ponto culminante para a preocupação da população foi a possibilidade de acontecerem os arrastões, e não sua efetivação. Essa possibilidade vem da existência da greve dos policiais que, em teoria, desemboca nesse tipo de crime. Exemplo semelhante e recente foi o da paralisação dos caminhoneiros (ocorrido em 2018). 0 fato de estes pararem seus veículos nas rodovias, com a retenção dos produtos, gerou na população o medo de que faltassem mercadorias nas prateleiras dos supermercados, o que a fez estocar gêneros alimentícios e combustíveis. Nenhum veículo oficial de comunicação ou a imprensa recomendou que as pessoas aderissem a tal prática, no entanto, a possibilidade de esgotamento gerou a efetiva carência, tanto de gasolina, como de determinados alimentos, além dela, a circulação de notícias falsas ${ }^{\mathrm{vi}}$. A hipertrofia da informação, portanto, apoia e é apoiada pela geração de fake news. Ambas atuam para que a população aja em resposta a um acontecimento de potencial interferência em sua vida. $\mathrm{O}$ fato é narrado dentro da possibilidade de caos (hipertrofia da informação) e se consuma a necessidade de ação por meio de notícias falsas (fake news). Em suma, a hipertrofia da informação, nesse sentido, é uma forma de espetacularização pautada em especulação.

Sítios que trabalham com a checagem de fatos já classificam fake news dessa natureza em suas verificações, mesmo que de forma indireta, como é o caso da Agência Lula. Nela, pode-se perceber a hipertrofia da informação nas etiquetas: informação exagerada (notícias cujas informações estão no caminho correto, mas há exagero); ainda é cedo para dizer (a informação pode vir a ser verdadeira, mas ainda não é) e insustentável (quando não há dados públicos que comprovem a veracidade da informação). Na página Aos fatos, a etiqueta que evidencia a hipertrofia da informação, também de forma indireta, é a de conteúdo 'exagerado'. Interessante destacar o uso destas etiquetas (ou tags) como forma de evidenciar que as notícias que compõem as fake news não são formadas exclusivamente por fatos inexistentes, mas pelo enviesamento de fatos. Esses enviesamentos passam despercebidos na medida em que o leitor apresenta pouca familiaridade com estratégias e ferramentas de checagem de fatos, bem como pela oferta massiva de informações diversas a respeito de outros temas, ou do mesmo tema, mas que tratam de desdobramentos diferentes. A hipertrofia da 
informação passa despercebida por seus leitores, dado que a hiperplasia de informações (ou hipertrofia numérica da informação), atrelada à neofilia, dificulta uma apreciação cautelosa do que se lê.

\section{CONSIDERAÇÕES FINAIS}

Ambas as hipertrofias, a espetacularizada e a numérica (hiperplasia), demonstram a fragilidade e inabilidade com que as pessoas lidam com a informação, mesmo em uma sociedade dita informacional. A informação, insumo para o conhecimento e para a verdade, torna-se, neste contexto, uma ferramenta de manipulação, quando em seu estado anômalo ou quando utilizado em hiperdosagem. Este produto, portanto, na atual sociedade, comporta-se como um pharmakon, que tanto tem a capacidade de curar a ignorância como promovê-la.

O desafio está justamente em como perceber a informação nos ambientes e espaços de comunicação. Não é à toa que estudos a respeito do tema fake news têm surgido no meio científico, e propagandas a respeito de seu combate têm aparecido nos meios de comunicação de massa, como a televisãovii. Outros atores comunicacionais, como o WhatsApp viii, têm se preocupado com a temática, elaborando políticas de combate à fake news e incentivando usuários a pensarem formas de evitar sua propagação, bem como de elaborar estratégias que podem ser utilizadas de forma automatizada.

Para além dessas reflexões, o olhar atento, investigativo e perspicaz, antes da replicação é, ainda hoje, o método mais eficaz de não propagação de notícias falsas. Esta forma de ação só se dá por meio da educação dos consumidores e produtores de informação. A hipertrofia da informação é apenas uma das anomalias informacionais que a atual sociedade enfrenta. $\mathrm{O}$ analfabetismo informacional e digital e o acirramento político são outras formas de dificuldade que as pessoas encontram e que tornam a internet espaço propício à propagação das fake news.

Esse campo de estudo é, nesse sentido, terreno fértil para a Ciência da Informação, que tanto pode desvelar este universo por uma abordagem tecno-social da interação dos usuários com esses replicadores de informações falsas, como pela abordagem da genuinamente social, a partir do estudo do comportamento dos usuários de redes sociais e suas habilidades frente a informações anômalas. 


\section{REFERÊNCIAS}

ABBAGNANO, N. Dicionário de filosofia. 5. ed. São Paulo: Martins Fontes, 2007. ALMEIDA, I. Será que você padece de neofilia? Gaudium Press, jul. 2010. Disponível em: http://senhoradasgracas.org.br/noticias/17 743/Artigo--Sera-que-voce-padece-deneofilia-.html. Acesso em: 7 jul. 2018.

ARENDT, H. Entre o passado e o futuro. 7. ed. São Paulo: Perspectiva, 2014.

ARENDT, H. Entre o passado e o futuro. 8. ed. São Paulo: Perspectiva, 2016.

BARRETO, P. Muniz Sodré, o 'cara' da comunicação no Brasil. Agência UFRJ de Notícias, Rio de Janeiro, abr. 2012. Disponível em: https://ufrj.br/noticia/2015/10/22/munizsodr-o-cara-da-comunica-o-no-brasil. Acesso em: 7 jul. 2018.

\section{BAUMAN, Z. Ensaios sobre o conceito de cultura. Rio de Janeiro: Zahar, 2012.}

BELO, F. Leitura da introdução sobre a verdade e a mentira em Nietzsche. In: BELO, F. Leituras de Aristóteles e de Nietzsche: a poética sobre a verdade e a mentira. Lisboa: Fundação Calouste Gulbenkian, 1994. p. 206263.

BOLER, M.; DAVIS, E. The affective politics of the "post-truth" era: Feeling rules and networked subjectivity. Emotion, Space and Society, v. 27, 2018, p. 75-85. Disponível em: https://www.sciencedirect.com/science/arti cle/pii/S1755458617301585. Acesso em: 13 ago. 2018.

CAMARGO, G. A. Sobre o conceito de verdade em Nietzsche. Revista Trágica: estudos sobre Nietzsche, v.1, n. 2, jul./dez. 2008. p.93-112. Disponível em: http://tragica.org/artigos/02/07-gustavocamargo.pdf. Acesso em: 28 jun. 2018.

CAPURRO, R.; HJORLAND, B. O conceito de informação. Perspectivas em Ciência da
Informação, v. 12, n. 1, p. 148-207, jan./abr. 2007.

CASADEI, E. B. A legitimação das redes sociais como fonte para o jornalismo sob a perspectiva dos códigos padrões de narração. Revista Ação midiática: Estudos em Comunicação Sociedade e Cultura, Curitiba, v. 2, n. 5, 2013. Disponível em: https://webcache.googleusercontent.com/se arch?q=cache:qdFSSSqmJj4J:https://revistas. ufpr.br/acaomidiatica/article/download/32 $170 / 21232+\& \mathrm{~cd}=5 \& \mathrm{hl}=$ pt-

$\mathrm{BR} \& \mathrm{ct}=\mathrm{clnk} \& \mathrm{gl}=\mathrm{br} \& \mathrm{client}=$ firefox $-\mathrm{b}-\mathrm{ab}$. Acesso em: 25 jun. 2018.

CAVALCANTE, I.; FIRMO, E. Seis anos da greve da PM no Ceará. O Povo, Fortaleza, [2018]. Disponível em:

https://especiais.opovo.com.br/6anosdagre vedapm/. Acesso em: 13 jul. 2018.

COSTA, A. H. V. da. A doutrina de Platão sobre a verdade. Ítaca, [S.l.], n. 15, out. 2010. Disponível em:

https://revistas.ufrj.br/index.php/Itaca/arti cle/view/269/251. Acesso em: 28 maio 2018.

DEMO, P. Ambivalência da Sociedade da Informação. Ci. Inf., Brasília, v. 29, n. 2, p. 3742, maio/ago. 2000. Disponível em: http://www.scielo.br/pdf/\%0D/ci/v29n2/a 05v29n2.pdf. Acesso em: 30 maio 2000.

\section{DESCARTES, R. Discurso do Método e As}

Paixões da Alma. São Paulo, Nova Cultural, 1987.

DUNKER, C. et al. Ética e pós-verdade. Porto Alegre: Dublinense, 2017.

FERNANDES, M. G. M. et al. Análise conceitual: considerações metodológicas. Rev. Bras. Enferm., Brasília, v. 64, n. 6, nov./dez. 2011, p. 1150-1156. Disponível em:

http://www.scielo.br/pdf/reben/v64n6/v6 4n6a24.pdf. Acesso em 10 jul. 2018. 
FERRARI, T. Ciência do Capital e a quimérica interface homem-máquina. Ciência e engajamento, Cadernos de Ciências Sociais, n. 1, São Paulo, 2005. Disponível em:

linkcomprimidotferrari. Acesso em: 7 jul. 2018.

FOUCAULT, M. Verdade e poder. In: FOUCAULT, M. Microfísica do poder. 1. ed. Rio de Janeiro: Edições Graal, 1979b. p. 1-14.

\section{GIL, A. C. Métodos e técnicas de pesquisa}

social. 6. Ed. São Paulo: Atlas, 2008.

GÓMEZ, M. N. G. de. Dos estudos sociais da informação aos estudos do social desde o ponto de vista da informação. In: AQUINO, Mirian de Albuquerque (org.). 0 campo da ciência da informação: gênese, conexões e perspectivas. João Pessoa: Editora UFPB, 2002.

GUERRA, P. Notas complexas. Mídia, complexidade e poder, nov. 2013.

Disponível em:

https://mediaetpotere.wordpress.com/2013 /11/12/notas-complexas/. Acesso em: 7 jul. 2018.

HALL, J. E.; GUYTON, A. C. Guyton \& Hall tratado de fisiologia médica. 13. ed. Rio de Janeiro: Elsevier, 2017.

KLINGEL, J.; BOYD, D. “Keep It Secret, Keep It Safe": Information Poverty, Information Norms, and Stigma. Journal of ASIS\&T, v. 64, n. 5, 2013. p. 981-991. Disponível em: https://onlinelibrary-

wiley.ez15.periodicos.capes.gov.br/doi/full/ 10.1002/asi.22800. Acesso em 19 jun. 2018.

\section{KUHN, T. A estrutura das revoluções}

científicas. 5. ed. São Paulo: Perspectiva, 1998. [Documento eletrônico]. Disponível em:

https://aprender.ead.unb.br/pluginfile.php/ 200850/mod_resource/content/1/Thomas $\% 20$ Kuhn\%20-

$\% 20 \mathrm{~A} \% 20$ Estrutura $\% 20$ das\%20Revolu\%C3 \%A7\%C3\%B5es\%20Cient\%C3\%ADficas.pdf. Acesso em: 29 jun. 2018.

KÜNSCH, D. A. Narrativa jornalística e reconstrução do Cosmos. In: CONGRESSO
BRASILEIRO DE CIÊNCIAS DA COMUNICAÇÃO, 29., 2006, Brasília. Anais... Brasília: INTERCON, 2006. Disponível em: http://www.intercom.org.br/papers/nacion ais/2006/resumos/R1091-2.pdf. Acesso em: 7 jul. 2018.

LE COADIC, Y. A ciência da informação.

Brasília: Briquet de Lemos, 2004.

LE GOFF, J. História e memória. Campinas: SP Editora Unicamp, 1990.

MARQUES, Â. C. S. Esfera pública, redes e jornalismo. Rio de Janeiro: E-papers, 2009.

MESSIAS, L. C. da S. Informação: um estudo exploratório do seu conceito em periódicos científicos brasileiros da área de Ciência da Informação. 184 f. Dissertação (Mestrado) Universidade Estadual Paulista, Faculdade de Filosofia e Ciência da Informação, Marília, 2005. Disponível em:

https://www.marilia.unesp.br/Home/PosGraduacao/CienciadaInformacao/Dissertaco es/messias_lcs_me_mar.pdf. Acesso em: 30 maio 2018.

NIETZSCHE, F. W. Sobre verdade e mentira no sentido extra-moral. São Paulo: Hedra, 2007. [documento eletrônico]. Disponível em:

https://drive.google.com/file/d/0B45SVqPP bFlzblJGSXVkb3Q1bm9LdHZTT1huZ09lODB 2NXIB/view. Acesso em: 28 jun. 2018.

PHILLIP, J. The genesis of infotoxin. [S.l.: s. n.] 1995. Disponível em:

https://www.regainyourbrain.org/regain_ar ticles/jeff\%20phillips\%20articles/phillips\% 20genesis\%20infotoxin.htm. Acesso em: 7 ago. 2018.

POPPER, K. Conjecturas e refutações: o progresso do conhecimento científico. Brasília: Ed. Unb, 1980. Disponível em: https://www.passeidireto.com/arquivo/195 40339/karl-popper---conjecturas-erefutacoes-1. Acesso em 30 jul. 2018.

PRODANOV, C. C.; FREITAS, E. C. Metodologia do trabalho científico: métodos e técnicas da pesquisa e do trabalho 
acadêmico. 2. Ed. Novo Hamburgo: Feevale, 2013.

\section{RANGEL, I. S. Contando histórias, fazendo}

história: formação continuada com os professores da educação infantil. 241 f. 2009. Tese (doutorado) - Centro de Educação, Universidade Federal do Espírito Santo, Vitória, 2009. Disponível em: http://portais4.ufes.br/posgrad/teses/nome tese_31_IGUATEMI\%20SANTOS\%20RANGEL .pdf. Acesso em: 15 ago. 2018.

\section{RODRIGUEZ, J. G. T. Etimología de}

hipertrofia. Chile: DeChile Etimologias, 20--.

SALZTRAGER, R.; LOURENÇO, F. T. As verdades em Foucault e Benjamin: uma contribuição ao campo da memória social. Revista Internacional Interdisciplinar INTERthesis, Florianópolis, v. 14, n. 1, p. 4159, jan. 2017. ISSN 1807-1384. Disponível em:

https://periodicos.ufsc.br/index.php/interth esis/article/view/1807-

1384.2017v14n1p41/32912. Acesso em: 06 jul. 2018.

SIQUEIRA, A verdade em Nietzsche: três apontamentos para entender o conceito. Colunas tortas, maio 2014. Disponível em: http://colunastortas.com.br/3apontamentos-sobre-a-verdade-emnietzsche/. Acesso em: 28 jun. 2018.

\author{
TARSK, A. A concepção semântica da \\ verdade. São Paulo: Ed. Unesp, 2007. \\ VILELA, A. N. de O.; IZIDORO, J. L. Os \\ fundamentos da verdade no pensamento de \\ René Descartes: uma relação à sua época, \\ uma proposta à nossa época. CES Revista, \\ [S.l.], v. 27, n. 1, p. 53-71, jun. 2015. \\ Disponível em: \\ https://seer.cesjf.br/index.php/cesRevista/a \\ rticle/view/309. Acesso em: 25 jun. 2018.
}

WARDLE, C. Fake news. It's complicated.

First Draft, Havard Kennedy School, 16 fev. 2017. Disponível em:

https://firstdraftnews.org/fake-newscomplicated/. Acesso em: 10 ago. 2018.

WATANABE, T. C.; SOARES, A. G. T. Informação e formação no pensamento de descartes: crítica e alternativa à filosofia e à educação escolástica. Educação e Filosofia, Uberlândia, v. 5, n. 2, p.1-22, dez. 2011. Disponível em: http://www.seer.ufu.br/index.php/Educaca oFilosofia. Acesso em: 11 jun. 2018.

\section{NOTAS}

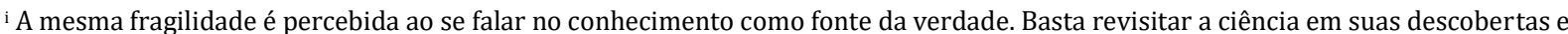
seus paradigmas, evidenciados por Kuhn (1998). A ciência normal de outrora não se compara com a ciência moderna, tanto pelos processos, quanto pelas ferramentas utilizadas para que as descobertas sejam feitas. 0 átomo como esfera indivisível já não atende à química atual, tampouco, a ideia de homossexualidade é tida hoje como patologia.

ii Ver em: https://piaui.folha.uol.com.br/lupa/. Acesso em: 10 out. 2018.

iii Ver em: https://www.youracclaim.com/badges/57582456-db4d-4541-beb0-eeb05d8ada75. Acesso em: 10 out. 2018.

iv Ver em: https://aosfatos.org/. Acesso em: 10 out. 2018.

v Texto original: "Information is not a stable, passive artifact in accounts from our participants; it is interactive, collective, and performative. Information is thus political in that it serves as the means of deciding who can be trusted and who cannot, who is a member and who is not"

vi Matéria G1 - dia 24 maio 2018. Ver em: https://g1.globo.com/economia/noticia/estoquem-comida-abastecam-seus-carrosnoticias-falsas-alimentam-panico-em-meio-a-greve-de-caminhoneiros.ghtml.

vii Ver mais em: Link de acesso. Acesso em: 23 ago. 2016.

viii Ver mais em: Link de acesso. Acesso em: 23 ago. 2016.
} 